\title{
Assessment of Knowledge, Attitude and Practice on Malaria Prevention Among Students of Hamelmalo Agricultural College
}

Minassie Mengisteab Araia ( $D$ mnasemengs2016@gmail.com )

Ministry of Health

Amanuel Hadgu Mebrahtu

National TB and Leprosy Control Program

Ghenet Weldegerghish

National Integrated Diseases Surveillance and Response Program, MoH, Asmara, Eritrea.

\section{Research}

Keywords: Malaria, Hamelmalo Agriculture College, Zoba Debub, Gash Barka zone

Posted Date: November 19th, 2020

DOl: https://doi.org/10.21203/rs.3.rs-110519/v1

License: (c) (i) This work is licensed under a Creative Commons Attribution 4.0 International License.

Read Full License 


\section{Abstract}

Background: Malaria is one of the most severe public health problems worldwide with 300 to 500 million cases and about one million deaths reported annually. In Eritrea, malaria is one of the major public health problems, particularly in Gash Barka zone which bears more than $60 \%$ of the burden.

Objective: To assess the knowledge, attitude, practice and misconceptions as well as association among knowledge of most vulnerable population and practice of the respondents on utilization of ITN with their demographic characteristics.

Methods: A cross-sectional study was conducted to assess KAP of Hamelmalo Agriculture College students in November 2016. Data was analyzed by SPSS version 20 and Stata version 13.

Results: (99.3\%) of respondents were aware of the existence of malaria as a disease. With regard to the malaria symptoms, fever was the most frequently reported by participant accounts $99.7 \% .70 .1 \%$ of respondents said they went to health facility if they get sick. Majority (85.1\%) of the respondents owned ITN but only $69.2 \%$ slept last night in ITN. 228 (77.55\%) perceive malaria as serious diseases only if it remains untreated however, $13(4.42 \%)$ as an ordinary disease. Some misconceptions were found on the assessment of the students on factors associated with malaria infection and health seeking behavior. The predictors of ITN utilization was found to be age 20 (OR18.49, ( $\mathrm{Cl}$ 1.227-278.87) $(\mathrm{P}=0.035)$ and being resident of Zoba Debub (OR 0.094, (Cl, 0.014-0.607)) (0.013) or Zoba Gash Barka (OR 0.027(Cl, 0.020.258) ( $P=0.002)$. The association between age of respondent and level of knowledge was found to be statistically significant with OR ranging from 3.9 up to 37.5 for the differ age groups.

Conclusion: The student of Hamelmalo Agricultural College has a fair knowledge, which is above $60 \%$ of the mean score and $50 \%$ on attitude and practice which is hard to accept, because we were proposing to get more than $50 \%$. So there are still areas that need to be addressed, since the students are likely to influence the behavior of their parents addressing the existing misconception is important.

\section{Background}

Malaria is one of the most severe public health problems worldwide with 300 to 500 million cases and about one million deaths reported annually, $\left.{ }^{[i]}\right] 85 \%-90 \%$ of which were reported from sub Saharan African

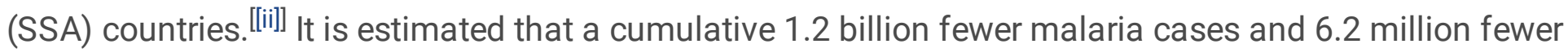
malaria deaths occurred globally between 2001 and 2015 than would have been expected, had incidence and mortality rates remained unchanged since 2000. In sub-Saharan Africa, it is estimated that malaria control interventions accounted for $70 \%$ of the 943 million reduction in malaria cases occurring between 2001 and 2015, averting 663 million malaria cases (range: 542-753 million). Of the 663 million cases averted due to malaria control interventions, it is estimated that $69 \%$ were prevented due to use of insecticide-treated mosquito nets (ITNs). [11]] 
In Eritrea, malaria is one of the major public health problems. The disease is particularly deadly in Gash Barka zone which bears more than $60 \%$ of the burden. Currently, the construction of mini-dams, introduction of irrigation schemes, traditional gold and other mining projects and movement of nonimmune people to these areas may worsen the malaria situation. $70 \%$ of the estimated population (nearly 2.4 million) resides in malaria endemic areas (41 out of the 58 Sub -zones). Malaria peaks up in October in most zones, while March-April is the main transmission season in the coastal area. Available data indicate that the disease burden due to malaria in Eritrea is decreasing from year to year. [2]]

According Malaria indicator and prevalence study [2012] result revealed Eritrea played a great role in malaria prevention activity, some of the activity carrier out by the MoH especially NMCP with its partners are, nearly half $(49.4 \%)$ of the households in zoba Debub and one-third (31.5\%) of households in zoba Gash-Barka were living in a dwelling sprayed with chemicals against malaria during the last 6 months. Regarding ownership and utilization of ITN, the percentage of households with at least one ITN was $86.6 \%$, with more than one ITN was $62 \%$ and with at least one LLIN was $85.8 \%$. The percentage of the population who slept under an ITN the night prior to the survey was $55.1 \%$. Among the population who live in households with at least one ITN, 62\% slept under an ITN the night prior to the survey. The above figure when we compare with global figure, for countries in sub-Saharan Africa, the estimated proportion with access to an ITN in their household was 56\% in 2014 (95\% confidence interval [CI]: 51-61\%) and $67 \%$ in 2015 (95\% Cl: $61-71 \%$ ) and for the utilization, the estimated proportion sleeping under an ITN was 46\% in 2014 (95\% Cl: $42-50 \%)$ and 55\% in 2015 (95\% Cl: 50-58\%). [1]

\subsection{General objective}

To assess knowledge, attitude and practice on malaria prevention among the students in Hamelmalo Agriculture College.

\subsection{Specific objective}

- To assess the knowledge of the students toward malaria prevention.

- To assess the attitude of the students toward malaria prevention.

- To assess the practice of the students toward malaria prevention.

- To assess the misconception of students in health seeking behavior and bed net utilization.

- To assess association between demographic characteristic of respondents and knowledge and practice

\subsection{Rationale}

In Eritrea, despite the intense activities pertaining to the distribution of ITNs, performing indoor residual spraying and provision of anti-malarial drugs free of charge, many questions about malaria remain unanswered. These includes, the extent to which people are aware of the benefit of ITNs, environmental 
management and IRS the value they give them, factors affecting its utilization and the individual and external factors influencing those interventions.

In Hamelmalo Agriculture College, although a variety of interventions were used against malaria prevention and control their utilization was low; for instance, students' possession of insecticide treated bed nets were appreciated, but the available ITNs were being utilized for other purposes than malaria prevention.

This study was conducted in order to know: how the students recognizes the causes, symptoms of malaria and prevention methods, why malpractice or low utilization of the ITN and whether there are any available IEC/BCC activities regarding malaria and its prevention which can in influencing the student's knowledge, attitude and practice towards different interventions, so having had such concepts this study would conducted.

\subsection{Significance of the study}

This student based study was conducted to investigate some of the gaps concerning knowledge, attitudes and practices toward malaria and its prevention methods among the students of Hamelmalo Agriculture College. Therefore, this study will generate vital information that has important contribution in the evidence based re-design of malaria control programs on higher board of education.

\section{Operational Definition}

Malaria Control: is a process that requires eradicating the carrier mosquito or reducing man-vector contact so as to cut in the life-cycle of the parasite.

Knowledge: what the individuals knows about malaria, its prevention and whether that knowledge is right or wrong

Attitude: the predisposition to respond in favor or un-favor toward malaria and its prevention.

Practice: regular utilization of malaria prevention interventions as part of their behavior.

Risk factor: mosquito breeding sites that may contribute for high risk of malaria.

Ordinal disease: is disease which can recover by its self within a short period of time without treatment.

Serious disease: a disease which needs diagnosis and treatment within short time after onset.

\section{Methods}

\section{Study area}

The study was conducted among students of Hamelmalo Agricultural College. We selected Hamelmalo Agriculture College from other colleges of Eritrea, due its geographical location favorable for malaria 
infections. HAC is located about $103 \mathrm{~km}$ north of Asmara, near the small administrative town of Hamelmalo in Anseba region. The college encircled by two rivers the one is Anseba River. Hamelmalo is $12 \mathrm{~km}$ outside Keren, on the Keren-Nakfa road. The College has been purposely located in a rural environment, providing ready access to agricultural land targeted for applied research and training purposes for students and staff. It has a total land area of 75 hectares.

At this time the college has eight faculties total of 1020 students. 720 in Degree and 300 Diploma, the faculties are Agricultural economics 87 students all degree, Agricultural Engineering 167 students 95 of them are in degree and 72diploma, Agro 123 students of them are 87 students degree and 36 diploma, Animal science 147 students of them 97 students are degree and 42diploma, HOSC (female Department they account 85\%) 139 students of them 97 students are in degree and 42 diploma, Land resources engineering 88students all degree, Plant resource 107 students of them 77students are degree and 30diploma, and Veterinary sciences students are also 153. Nine students are also withdrawals in this academic year.([1])

Study design

A college student based cross-sectional survey was conducted to assess KAP of student on malaria prevention.

Sample size determination and Sampling procedures

\section{Sample size}

The sample size for this study was calculated using the single population proportion formula shown below.

$$
\mathrm{n} 1=\mathrm{z}^{2} \mathrm{p} \frac{(1-\mathrm{p})}{\mathrm{d}^{2}}
$$

Where:

$\mathrm{n} 1=$ calculated sample size

$Z=$ the standard score for $95 \%$ confidence interval, which is 1.96

$\mathrm{P}=$ proportion of knowledge, which is taken as $50 \%$

$D=$ margin of error, which is taken 0.05

By using this formula, the initial sample size was found to be 384 . Then we used the adjustment formula shown below to make correction to the sample size based on the population size. 
$\mathrm{N} 2=\frac{\mathrm{n} 1 * \mathrm{~N}}{\mathrm{n} 1+\mathrm{N}}$

Where:

$\mathrm{N}=$ the total target population, 1012

$\mathrm{n} 1=$ the initial sample size, 384

$\mathrm{n} 2=$ the final sample size

Based on the adjustment formula the sample size was 279 . We added a $10 \%$ for non-response and the final sample size was 308 .

\section{Sampling technique}

We used a stratified sampling method to select the study participants. First we divided the student in to two groups based on study program, degree and diploma. Then with in these strata we further divided the students in a more homogenous strata based on study area. Then we allocated the sample size among the strata proportional to the size of each strata. Finally, we used systematic random sampling to select study participants.

Inclusion and exclusion Criteria

Inclusion criteria

- Undergraduate student currently, during study period, enrolled in the college

- Student in year of study from second year through fifth year, and;

- Students who were willing to take part in the study and who provide informed consent

\section{Exclusion Criteria}

- Students of Master program

- Severely sick students

- Students who have had malaria 6 months prior to the study period

Variables

Dependent Variables

Knowledge, attitude and practices towards Malaria prevention were the dependent variables. 
Socio-demographic characteristics (age, sex, religion, ethnicity, study year, level of education status and permanent address.)

\section{Data collection}

Data was collected using a self-administered questionnaire developed by the research team, through consultation of other questionnaires and various expertise. The questionnaire included three parts. The first part had questions on socio-demographic details of respondents. The second part had questions related to knowledge about malaria transmission, treatment and prevention, and attitude towards the disease. The third section paid attention to prevention and treatment practices of the respondents.

Before we go the actual work the questioner was tested in ACHS students as a pilot study, for the clarity of the words, flow of the questions, measuring time and other unforeseen problems. After the pilot study the questionnaire was finalized based on the information gathered. Before we distribute the questionnaire to the students, orientation was carried out by the researcher team. Respondents filled the questionnaires in their class.

\section{Data analysis}

After data collection, the questionnaires were checked for completeness and data cleaning was done by the research team. Data was entered in Epi-info version 7 and generated to excel sheet, finally analyzed by SPSS version 20 and Stata version 13. Simple frequencies and summary measures were used to describe demographic variables. Logistic regression analysis was used to assess for association between the dependent and independent variable. Odds ratio (OR) with its $95 \%$ confidence intervals was used to show the strength of association. $P=$ values of $<0.05$ was considered as statistical significant association. Summary data is presented in the form of graphs and frequency tables.

\section{Results}

This chapter presents the results of the study. It starts with the demographic characteristics of the respondents followed by the summary findings of the knowledge, attitude, practice questions result and misconception. Finally, it presents the main findings of the association analysis between dependent and independent variables.

308 students selected for the study, 302 were participated, yielding a response rate of $98.5 \%$. Out of the 302 respondents $51 \%$ were males and (49\%) are females. Mean age of the respondents was $20.42 \mathrm{yrs}$ (SD 2.873). The percentage of respondents in descending order by zone was Maekel (54.4\%) followed by Debub (20.4\%), Anseba (12.9\%), Gash Barka (9.2\%), Northern Red sea (1.7\%), and Southern Red Sea (1.4\%). With regard to ethnicity, $87.4 \%$ of the respondents were from Tigrigna and the rest from Tigre, Saho, Bilen, Hidareb, and Kunama ethnicities. Majority of the respondents were degree students $67.9 \%$ and second year students $49.7 \%$. (Table 1)

Table 1 shows the socio-demographic characteristics of the students. $(n=302)$ 


\begin{tabular}{|c|c|c|c|}
\hline Variables & & Frequency (n) & Percent (\%) \\
\hline \multicolumn{4}{|l|}{ Age } \\
\hline & 18 & 16 & 5.3 \\
\hline & 19 & 94 & 31.1 \\
\hline & 20 & 92 & 30.5 \\
\hline & 21 & 51 & 16.9 \\
\hline & 22 & 21 & 7 \\
\hline & 23 & 16 & 5.3 \\
\hline & $>24$ & 11 & 3.6 \\
\hline \multicolumn{4}{|l|}{ Sex } \\
\hline & Male & 154 & 51 \\
\hline & Female & 148 & 49 \\
\hline \multicolumn{4}{|c|}{ Respondents study program } \\
\hline & Diploma & 97 & 32.1 \\
\hline & Degree & 205 & 67.9 \\
\hline \multicolumn{4}{|c|}{ Year of study } \\
\hline & $2^{\text {nd }}$ & 150 & 49.7 \\
\hline & $3^{\text {rd }}$ & 82 & 27.2 \\
\hline & $4^{\text {th }}$ & 63 & 20.9 \\
\hline & $5^{\text {th }}$ & 7 & 2.3 \\
\hline \multicolumn{4}{|c|}{ Permanent Address of Respondents } \\
\hline & Maekel & 160 & 53 \\
\hline & Debub & 60 & 19.9 \\
\hline & Anseba & 38 & 12.6 \\
\hline & G/Barka & 27 & 8.9 \\
\hline & NRS & 5 & 1.7 \\
\hline & SRS & 4 & 1.3 \\
\hline \multicolumn{4}{|c|}{ Respondents Ethnic group } \\
\hline & $\begin{array}{l}\text { Tigrigna } \\
\text { ye } 8 / 24\end{array}$ & 264 & 87.4 \\
\hline
\end{tabular}




\begin{tabular}{|llll|}
\hline Tigre & 17 & 5.6 \\
\hline Afar & 1 & 0.3 \\
\hline Saho & 6 & 2 \\
\hline Bilen & 11 & 3.6 \\
\hline Hidareb & 2 & 0.7 \\
\hline Kunama & 1 & 0.3 \\
\hline
\end{tabular}

Table 2: Knowledge of existence of malaria as disease and knowing of $s / s$ of malaria $(n=302)$

\begin{tabular}{|llll|}
\hline Variables & & Yes (\%) & No (\%) \\
\hline Existence of malaria as a disease & & & \\
\hline S/S of Malaria & Fever & $300(99.3 \%)$ & $1(0.003 \%)$ \\
\hline Headache & $284(94.4 \%)$ & $17(5.6 \%)$ \\
\hline Chills & $218(72.4 \%)$ & $83(27.6 \%)$ \\
\hline Thirsty/poor Appetite & $167(55.5 \%)$ & $134(44.5 \%)$ \\
\hline Joint pain & $171(56.8 \%)$ & $130(43.2 \%)$ \\
\hline Nausea \&vomiting & $112(37.2 \%)$ & $189(62.8 \%)$ \\
\hline Diarrhea & $36(12 \%)$ & $265(88 \%)$ \\
\hline
\end{tabular}

\section{Knowledge of respondents on malaria}

Almost all the respondents (99.3\%) were aware of the existence of malaria as a disease. With regard to the malaria symptoms, fever was the most frequently reported by participant accounts $94.4 \%$, followed by headache $(72 \%$, ) and chills $(80.2 \%)$. And $12 \%$ of the respondents reported diarrhea as a symptom of malaria. (Table 2

Out of those who knew malaria as a transmittable disease ( $n=255), 235$ (92.5\%) mentioned mosquito bite as a means of malaria transmission, however $(11.3 \%)$ stated by breathing, $(1.96 \%)$ by housefly and $(1.96 \%)$ by body contact. With regard to the knowledge of mosquito breeding sites and biting time, $202(66.8 \%)$ of the respondents mentioned stagnant water and waste material as mosquito breeding site, 
and 95 (31.5\%) stated mosquito breed in running water. With regard to knowledge on mosquito bite 293(97\%) mentioned mosquito bites during the night and 3 (1\%) during the day. (Table3)

Table 3: Knowledge of malaria transmission and mosquito breeding site

\begin{tabular}{|c|c|c|c|}
\hline Variables & & Yes \% & No $\%$ \\
\hline Malaria is transmittable Disease & & $255(85 \%)$ & $46(15.3 \%)$ \\
\hline \multirow{3}{*}{$\begin{array}{l}\text { Malaria mode } \\
\text { Transmission }(n=255)\end{array}$} & Mosquito bite & $235(92.5 \%)$ & $19(7.5 \%)$ \\
\hline & Breathing & $29(11.3 \%)$ & $225(98 \%)$ \\
\hline & Housefly & $5(1.96 \%)$ & $250(98.4 \%)$ \\
\hline \multirow[t]{4}{*}{ Mosquito breeding site $(n=300)$} & Body contact & $5(1.96 \%)$ & $250(98.4 \%)$ \\
\hline & Stagnant water & 299(99\%) & $1(0.3 \%)$ \\
\hline & Running Water & $95(31.5 \%)$ & $205(67.9 \%)$ \\
\hline & West material & $202(66.9 \%)$ & $98(32.5 \%)$ \\
\hline
\end{tabular}

The table 4 result shows, $94.7 \%$ of the study group stated that, use of mosquito bed net is the most preventive method to prevent malaria infection, $69.5 \%$ by using indoor residual spry (IRS), $(92.4 \%)$ by draining stagnant water, $76.8 \%$ by Clear vegetation, however, $28.5 \%$ and $21.5 \%$ of our study group mentioned IRS and clearing vegetation is not preventing malaria infection.

Table 4: respondent knowledge on malaria preventive measures 


\begin{tabular}{|llll|}
\hline Variables & \multicolumn{1}{l}{ Yes $\%$} & No $\%$ \\
\hline Is Malaria preventable(N=302) & & $299(99 \%)$ & 0 \\
\hline Mode of prevention (N=299) & & & \\
& Use Mosquito net & $286(94.7 \%)$ & $11(3.6 \%)$ \\
\cline { 2 - 4 } & IRS & $210(69.5 \%)$ & $86(28.5 \%)$ \\
\hline & Draining stagnant water & $279(92.4 \%)$ & $18(6 \%)$ \\
\cline { 2 - 4 } & Clear vegetation & $232(76.8 \%)$ & $65(21.5 \%)$ \\
\cline { 2 - 4 } & Taking tablet & $233(77.2 \%)$ & $64(21.2 \%)$ \\
\hline & Close window \&doors & $175(57.9 \%$ & $122(40.4 \%)$ \\
\hline
\end{tabular}

\section{Computed knowledge score of respondent}

Generally, according to our finding from all those computed variables on assessing knowledge, above $60 \%$ of the respondents found to have fairly good knowledge.

\section{Attitude of respondent towards malaria}

The result of the attitude toward malaria prevention shows that, $228(77.55 \%)$ of the respondents perceive malaria as serious diseases only if it remains untreated, $53(18.03 \%)$ as a serious disease and $13(4.42 \%)$ as an ordinary disease. (Figure 4.1$)$

\section{Computed attitude score of respondent}

Generally, according to our finding of the result we found the computed attitude from all the computed variables is fairly poor which about $50 \%$ on malaria prevention.

\section{Practice of respondents towards malaria prevention}

Regarding malaria practice and preventive measures, 212 (70.1\%) of respondents said they went to health facility if they get sick, followed by pharmacy 135 (44.7\%), traditional healers 8 (2.6\%), use leftover drugs $10(3.3 \%)$ and use home remedies $22(7.4 \%)$. With regard to the ownership of ITN, 257/302 (85.1\%) of the respondents owned ITN. However, utilization of ITNs during the last night was 204 (69.2\%). For those who did not used ITNs ( $\mathrm{n}=91$ ), did not used ITN last night because, not suitable to hung 29 (31.9\%), don't believe it prevents from mosquito bite 4(4.3\%), no mosquito last night 14 (15.1\%),6 (6.1\%) due to hot weather and 39 (41.9\%) of the respondents missed to answer. 


\section{Computed practices score of respondent}

Generally, according to our finding, the computed practice variable on malaria prevention and health seeking behavior of the respondents is fairly poor which about $50 \%$.

\section{Misconception of respondents on malaria treatment seeking behavior}

According the table 5 result shows the misconception of the study group, when the age of the students increased the misconception regarding health seeking behavior of the students in using traditional healers increased from $2.4 \%$ to $9.09 \%$ among the age group of $>24$ years, however in use traditional remedy at how $(7.9 \%)$ and $3.6 \%$ used others leftover drugs to treat malaria in age group of $18-23$.

Table 5: respondents' misconception 
Variables

Age

\begin{tabular}{|c|c|c|}
\hline $18-23$ & $2.40 \%$ & $3.46 \%$ \\
\hline$>24$ & $9.09 \%$ & $0 \%$ \\
\hline
\end{tabular}

Sex

\begin{tabular}{llll} 
Male & $3.90 \%$ & $5.20 \%$ & $7.80 \%$ \\
\hline Female & $1.40 \%$ & $1.40 \%$ & $6.80 \%$ \\
\hline
\end{tabular}

\section{Study Year}

\begin{tabular}{llll}
$\mathbf{2}$ & $1.30 \%$ & $3.30 \%$ & $5.30 \%$ \\
\hline $\mathbf{3}$ & $6.10 \%$ & $6.10 \%$ & $15 \%$ \\
\hline $\mathbf{4}$ & $0 \%$ & $0 \%$ & $3.10 \%$ \\
$\mathbf{5}$ & $14.20 \%$ & $0 \%$ & $0 \%$ \\
\hline
\end{tabular}

Level of

Education

\begin{tabular}{|llll}
\hline Degree & $1.90 \%$ & $2.90 \%$ & $6.80 \%$ \\
\hline Diploma & $4.10 \%$ & $4.10 \%$ & $8.20 \%$ \\
\hline
\end{tabular}

Zoba

\begin{tabular}{llll} 
Maekel & $3.30 \%$ & $1.80 \%$ & $7.50 \%$ \\
\hline Debub & $5 \%$ & $3.30 \%$ & $6.60 \%$ \\
\hline Anseba & $2.60 \%$ & $2.60 \%$ & $7.80 \%$ \\
\hline $\begin{array}{l}\text { Gash } \\
\text { Barka }\end{array}$ & $0 \%$ & $3.70 \%$ & $3.70 \%$ \\
\hline NRS & $0 \%$ & $0 \%$ & $0 \%$ \\
\hline SRS & $25 \%$ & $25 \%$ & $25 \%$ \\
\hline
\end{tabular}

Ethinic

\begin{tabular}{llll} 
Tigrgna & $2.60 \%$ & $3.03 \%$ & $7.20 \%$ \\
\hline Tige & $0 \%$ & $6.25 \%$ & $0 \%$ \\
\hline Afar & $100 \%$ & $100 \%$ & $100 \%$ \\
\hline Saho & $0 \%$ & 0 & $16.60 \%$ \\
Bilen & $0 \%$ & $\begin{array}{c}0 \% \\
\text { Page } 13 / 24\end{array}$ \\
\hline
\end{tabular}




\begin{tabular}{|llll|}
\hline Hidareb & $0 \%$ & $0 \%$ & $0 \%$ \\
\hline Kunama & $0 \%$ & $0 \%$ & $0 \%$ \\
\hline
\end{tabular}

With regard sex of the respondent misconception on health seeking behavior was found more in male than female. Among the students attending in $5^{\text {th }}$ year $(14.2 \%)$ shown more

\section{Misconception of respondents' knowledge factors that associated with malaria}

The major finding (table 6) revealed that, the misconceptions of the students on factors that associated with malaria infections. Among the age group 18-23 the students mentioned that malaria is associated with eating maize stalk (27.9\%), cloudy weather $(24.4 \%)$ and cold weather $(30.4 \%)$, followed by in age group of $>24,(54.4 \%)$ eating maize stalk, $(54.4 \%)$ cloudy weather and $(45.4 \%)$ cold weather.

Table 6: Misconception of respondents' knowledge factors that associated with malaria 
Variables

Age

\begin{tabular}{llll}
$\mathbf{1 8 - 2 3}$ & $27.90 \%$ & $24.47 \%$ & $30.40 \%$ \\
\hline $\mathbf{2 4}$ & $54.50 \%$ & $54.50 \%$ & $45.40 \%$
\end{tabular}

Sex

\begin{tabular}{llll} 
Male & $33.50 \%$ & $28.90 \%$ & $28.90 \%$ \\
\hline Female & $23.90 \%$ & $21.90 \%$ & $32.80 \%$ \\
\hline
\end{tabular}

\section{Study Year}

\begin{tabular}{llll}
$\mathbf{2}$ & $23.10 \%$ & $23.10 \%$ & $31.90 \%$ \\
\hline $\mathbf{3}$ & $34.50 \%$ & $30.80 \%$ & $34.50 \%$ \\
\hline $\mathbf{4}$ & $33.30 \%$ & $25.30 \%$ & $26.90 \%$ \\
\hline $\mathbf{5}$ & $42.80 \%$ & $28.50 \%$ & $0 \%$ \\
\hline
\end{tabular}

Level of

\section{Education}

\begin{tabular}{llll} 
Degree & $27.70 \%$ & $22.70 \%$ & $24.70 \%$ \\
\hline Diploma & $31.20 \%$ & $31.20 \%$ & $43.70 \%$
\end{tabular}

\section{Zoba}

\begin{tabular}{llll} 
Maekel & $21.00 \%$ & $25.40 \%$ & $30.50 \%$ \\
\hline Debub & $38.30 \%$ & $31.60 \%$ & $35 \%$ \\
\hline Anseba & $42.20 \%$ & $15.70 \%$ & $26.30 \%$ \\
\hline $\begin{array}{l}\text { Gash } \\
\text { Barka }\end{array}$ & $41 \%$ & $1.50 \%$ & $34.60 \%$ \\
\hline NRS & $0 \%$ & $40 \%$ & $20 \%$ \\
\hline SRS & $25 \%$ & $50 \%$ & $25 \%$ \\
\hline
\end{tabular}

Ethinic

\begin{tabular}{|llll|}
\hline Tigrgna & $28.10 \%$ & $24.60 \%$ & $30.30 \%$ \\
\hline Tige & $29.40 \%$ & $29.40 \%$ & $23.50 \%$ \\
\hline Afar & $100 \%$ & $100 \%$ & $100 \%$ \\
\hline Saho & $33.30 \%$ & $66.60 \%$ & $33.30 \%$ \\
\hline Bilen & $45.40 \%$ & $18.10 \%$ & $45.40 \%$ \\
\hline
\end{tabular}




\begin{tabular}{|llll|}
\hline Hidareb & $0.00 \%$ & $0 \%$ & $50 \%$ \\
\hline Kunama & $0 \%$ & $0 \%$ & $0 \%$ \\
\hline
\end{tabular}

With regard to place of origin those who came from Anseba zone accounts (42\%) by eating maize stalk, $(15.7 \%)$ by cloudy weather and $(26.3 \%)$ by cold weather were mentioned as associating factors, followed by $(38.3 \%)$, eating maize stalk, $(31.6 \%)$ cloudy weather and $(35 \%)$ cold weather from Debub region. With regard ethnicity of the respondents, $(100 \%)$ of those who came from Afar ethnic group believe that malaria is associated with eating maize stalk, cloudy and cold weather, followed by (45.4\%), eating maize stalk, $(18.1 \%)$ cloudy weather and $(45.4 \%)$ cold weather from Bilen ethnic group. (table 6$)$

\subsection{Determinants of KAP of malaria}

\subsubsection{Association between background variables and respondents' knowledge}

The association between knowledge of vulnerable groups with age and year of study of respondents were analyzed. The association between age of respondent and level of knowledge was found to be statistically significant with OR ranging from 3.9 up to 37.5 for the differ age groups. With regard to year of study and level of knowledge, being third year student was a predictor to have a lower knowledge as compared to the reference second year students (OR $0.365(\mathrm{Cl}, 0.145-0.921))(P=0.033)$. However, there were no statistical significant difference between the other years of study and the reference category, second year. (Table: 7)

Table 7: association between knowledge of vulnerable groups with age and year of study of respondents 


\begin{tabular}{|c|c|c|c|c|c|}
\hline Variable & & Adequate $\mathrm{n}(\%)$ & In Adequate n (\%) & $\mathrm{OR}(95 \% \mathrm{Cl})$ & P-Value \\
\hline \multicolumn{6}{|l|}{ Age } \\
\hline & $18^{\mathrm{a}}$ & $2(12.5 \%)$ & $14(87.5 \%)$ & 1 & \\
\hline & 19 & $21(22.3 \%)$ & 73(77.7\%) & $3.921(1.304-11.788)$ & $0.015^{\star \star}$ \\
\hline & 20 & $26(28.3 \%)$ & $66(71.7 \%)$ & 6.894(1.910-24.880) & $0.003^{\star * \star}$ \\
\hline & 21 & $15(29.6 \%)$ & $36(70.6 \%)$ & $6.497(1.516-27.843)$ & $0.012^{\star \star}$ \\
\hline & 22 & $2(9.5 \%)$ & $19(90.6 \%)$ & $37.560(2.770-509.186)$ & $0.006^{\star \star}$ \\
\hline & 23 & $2(12.5 \%)$ & $14(87.5 \%)$ & 7.353 (1.213-44.560) & $0.03^{\star *}$ \\
\hline \multicolumn{6}{|c|}{ Study year } \\
\hline & $2^{a}$ & $39(26 \%)$ & $111(74 \%)$ & & \\
\hline & 3 & $20(24.4 \%)$ & $62(75.6 \%)$ & $0.365(0.145-0.921)$ & $0.033^{\star *}$ \\
\hline & 4 & $11(17.5 \%)$ & $52(82.5 \%)$ & $1.071(0.299-3.839)$ & 0.915 \\
\hline & 5 & $1(14.3 \%)$ & $6(85.7 \%)$ & $0.143(0.0153-1.334)$ & 0.088 \\
\hline
\end{tabular}

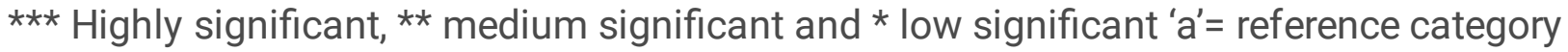

\subsubsection{Association between background variables and respondents practice}

The association between bed net utilization with age and place of residence was assessed using logistic regression. The results revealed that practice of mosquito bed net utilization to be significantly associated with the age and permanent address of the respondents. The predictors was found to be age 20 (OR18.49, ( $\mathrm{Cl}$ 1.227-278.87) ( $P=0.035)$ and being resident of Zoba Debub (OR 0.094, (Cl, 0.014-0.607)) (0.013) and Zoba Gash Barka (OR 0.027(Cl, 0.02-0.258) $(\mathrm{P}=0.002)$. For the other variables are no association shown. (Table: 6)

Table 6: logistic regression analysis practice on bed net utilization on demographic characteristics of the respondents 


\begin{tabular}{|lllll|}
\hline & Yes n (\%) & No n (\%) & OR (95\% Cl) & P-Value \\
\hline Age & & & & \\
\hline 18 & & & 1 & \\
\hline 19 & $85(90.4 \%)$ & $6(6.4 \%)$ & $0.795(0.098-6.442)$ & 0.831 \\
\hline 20 & $85(90.4 \%)$ & $1(1.08 \%)$ & $18.49(1.227-278.87)$ & $0.035^{\star *}$ \\
\hline 21 & $48(94.1 \%)$ & $2(3.9 \%)$ & $3.55(0.170-74.276)$ & 0.413 \\
\hline Zoba & & & & \\
\hline Maekel & & & & \\
\hline Debub & $55(92 \%)$ & $4(7 \%)$ & $0.094(0.014-0.607)$ & $0.013^{\star *}$ \\
\hline Anseba & $36(95 \%)$ & $2(5 \%)$ & $0.165(0.020-1.347)$ & 0.093 \\
\hline GashBarka & $24(89 \%)$ & $3(11 \%)$ & $0.027(0.02-0.258)$ & $0.002^{\star * *}$ \\
\hline
\end{tabular}

*** Highly significant, ** medium significant and * low significant a= reference category

\section{Discussion}

It is very crucial that individuals should know about malaria and its prevention and control methods for the success of malaria control programs. This is because, that adequate knowledge about malarial will rise the people's awareness towards the disease which will eventually lead to a good practice towards the prevention and control methods.

In this study a total of 302 students of HAC were participated. The mean ages of the students were 20.6 years. Male to female ratio of the participants was almost similar ( $51 \%, 49 \%$ respectively). Majority of them (87\%) were from the Tigrigna ethnic group and Afar and Kunama being the least $(0.3 \%)$. Zoba Maekel account for almost half of the respondents' place of permanent residency $53 \%$ followed by Zoba Debub and Anseba $19.9 \%$ and $12.6 \%$ respectively. Degree program respondents accounts for up to $67 \%$ of the participants. The second year students alone cover almost half (49.7\%) of the study participants.

This study has shown a relatively good knowledge about malaria as it was evident that $30299.3 \%$ were aware of the existence of malaria as a disease, this result is relatively high when comparing with students of Dow university in Pakistan [[1]] where it was (91.1\%). The variation of knowledge may be due to difference in geographical location and the presence of strong ACSM activity of the NMCP and ZMCP in the current college.

Regarding knowledge of the signs and symptoms, fever and chills was identified by the majority (77.4\%). However, $12 \%$ of the respondents identified diarrhea as a sign of malaria, which was wrong. This 
misconception may affect the health seeking behavior of the individuals because, if a student believes that diarrhea is the sign of malaria he/she may not seek medical help even if he/she have fever and chills. When we compare the result with study from Dow University, Pakistan [4], reported symptoms were fever and shivering by $75.8 \%$, loss of appetite by $30 \%$ and nausea by $27.1 \%$. And form another study conducted in Legos University, Nigeria [[2]] the most obvious sign of malaria to the students was headache $49.6 \%$. When we compare the result of our study with these studies respondent in our study had a higher knowledge about malaria signs and symptoms. This difference can be due to difference in awareness raising programs between the three settings or it can also be due to cultural difference in the way of reporting health problems, chief compliant.

Eighty-five percent of the respondents in the current study new malaria as transmittable disease and the knowledge on the means of malaria transmission were very satisfactory, in which the vast majority (92.5\%) of respondents identified mosquito bite as a means. However, breathing and houseflies were reported as a means of transmission by $11.3 \%$ and $1.6 \%$ of the respondents. This misconception can affect the utilization of ITNs, if a person believes malaria is transmitted by breathing and houseflies he/she may not understand the use of the ITNs. As a result, even if they have ITNs, they may it for other purposes like as a screen or curtain for doors and windows to prevent houseflies from getting to the house. When we compare this finding with other studies, similar result was shown in a study from Dow University, Pakistan, where $92.92 \%$ of the respondent identified mosquito bite as a means of transmission, $7.1 \%$ dog bite and $18.78 \%$ believe that malaria can be transmitted by body contact [4].

One of the most effective personal preventive methods of malaria infection is using of ITN and IRS. HAC have no experience of using IRS to prevent malaria. However, $85.1 \%$ of the respondents owned ITN. Out of those who owned ITNs only $69.2 \%$ slept in it the night before the data collection. This result is slightly higher than the study conducted among Dow University in Pakistan students, where only $54.75 \%$ of the student slept in ITNs (4). One third of our respondent are not using ITN to prevent malaria, according to our study findings the reasons were, not suitable to hung $31.9 \%$, no mosquito last night $15.1 \%$, due to hot weather $6.1 \%$, and don't believe it prevents from mosquito bite $4.3 \%$. As we can see from the figures the most important reason was not suitable to hang and giving attention to this problem can result in immediate and substantial increase in ITN utilization.

The college has good practice regarding environmental activity to control the mosquito breeding sites. As a result, $85.8 \%$ of the respondents had participated in environmental control strategy. The community of the HAC had good practice of environmental control strategy activities, routinely all students; academic and administrative staff takes part in the activity. Nonetheless, based on our observation, despite all the effort made by the college community, the college has much stagnant water in front of the dormitories.

Attitude was one of the components of our study, and $75.5 \%$ the respondents believe that malaria is a serious disease if left untreated in a time and $17.5 \%$ said it is serious disease in its own right, regardless of treatment. But it was also mention as an ordinary or simple disease by about $4.3 \%$ of the respondent. 
The above result shows the students have good attitude about the seriousness of malaria, which can boost the desire to use the ITNs.

To identify association between the dependent variable, KAP of malaria, and the independent variables, demographic characteristics, logistic regression analysis was performed. In doing so the lowest age (18), was used as reference to assess the relationship between age of the respondents and knowledge of malaria. The results of logistic regression showed that age of the respondents as a predictor of good knowledge of the disease. That is as the age of the student increases the level of knowledge about malaria also increases. To assess the association between year of study and level of knowledge, second year was used as reference category. The results of the analysis show no significant difference in knowledge level between the reference category (second year) and fourth year ( $P=0.915)$ and fifth year $(P=0.088)$ respondents. However, being third year was found to be a predictor for lower level of knowledge $(P=0.033)$.

The result of association between bed net utilization with age and place of residence showed that, ITN utilization to be significantly associated with the age and permanent address of the respondents. The predictors for ITN use were found to be age 20 and being resident of Zoba Debub ( $P=0.013)$ and Zoba Gash Barka ( $P=0.002)$. This association of ITN use and place of resident can be due to the prevalence of the disease in these zobas which makes the respondents to be more aware about the benefits of the ITNs. For the other variables the results of logistic regression show no significant difference.

[1]Mushtaq Ahmed, Rafaqat BOTA, Muhammad Salah Jamali, Adnan Aziz, Tayyaba llyas Dow Medical College; Civil hospital Karachi, Dow Medical College, Pakistan:MALARIA AND CONGO FEVER: AWARENESS AMONG UNIVERSITY STUDENTS Volume 2, Issue 1, 2013)

[2] Omolade O. Okwa and Adejoke C. Ibidapo: The Malaria situation, perception of cause and treatment in a Nigerian University. Journal of Medicine and Medical Sciences Vol. 1(6) pp. 213-222 July 2010

\section{Conclusion}

The findings of this study shows that the respondents had very good knowledge on existence of malaria as a disease, it's Signs and symptoms, treatment seeking behavior, and vector of transmission. However, there are some gaps in certain critical areas of knowledge like there were some misconceptions with regard to ways of malaria transmission. The practice of ITN usage is encouraging, although it was low as compared to the ITN ownership. The main hindering factors for ITN utilization were having difficulty in hanging the net and hot climate. This problem can be solved easily by identifying means on how to properly hang the nets. Nonetheless, we need to correct the belief that ITNs cannot prevent mosquito bites. Some of the respondents had mentioned using leftover drugs, visit to traditional healers and home remedies to treat malaria. This is a critical condition which needs immediate action, since untreated malaria can develop in to complicated severe malaria and serve as a source of disease transmission. All in all, the research team concludes that the student of Hamelmalo Agricultural College has a satisfactory KAP towards malaria prevention. But we still consider that there are areas that need to be addressed, 
since the students are likely to influence the behavior of their parents addressing the misconception will have a lasting effect that goes in to the community.

\section{Recommendations}

1. Even though the students had good knowledge about malaria, regular awareness rising seminars should be conducted to fight the misconceptions.

2. There needs to be a strict control in the proper use of the ITNs as it was revealed that many of the ITNs was used for other purposes.

3. The dormitory administrators of the college have to come up with a solution, which enables easy hanging of the bed nets.

Despite the good practice of the environmental control strategy, in order to keep the nearby environment of their dormitories, the administration of the college should be organized regular and routing environmental sanitation.

\section{Declarations}

\section{Ethics approval and consent to participate}

This study was reviewed and approved by the research review committee of The School of Public Health, ACHS. Official letter was written by the School of Public Health, Asmara college of Health Science, to HAC. The letter explained the importance of the study and the study was approved to be conducted in the college by the college authorities. Informed consent was obtained from each individual participant before they start to fill the questionnaire and the participants were free to leave the study at any point. Confidentiality was maintained by collecting data anonymously and by using the data only for the purposes of this study.

\section{Consent for publication}

The Authors agree to publish the research paper and the Collage of Health Sciences also informed.

\section{Availability of data and material}

Not applicable for this section.

\section{Competing interests}

Not applicable for this section.

\section{Funding}

The Asmara Collage of Health Science covered the research in cash form. 


\section{Authors' contributions}

We (the Authors') from the beginning preparation of the proposal research, data collection and reporting writing participated equally.

\section{Acknowledgements}

We would like to thank $C D C$ for providing an opportunity to participate in this special course and the staff members who covered our tasks while we are in the training.

We would like to thank especially our adviser Dr. Eyob Azeria (Head of school of Public Health, ACHS), Coordinator of this program Mr. Amaniuel Kidane (Epidemiologist and Bio-statistician, ACHS) and Mr. Eyasu (Bio-statistician, ACHS) for their support and guidance which was instrumental for completing the course and thesis successfully.

We convoy our special gratitude to the Director of CDC Dr. Araia Berhane, for his support and guidance in reviewing our questionnaire, and also Mr. Asmorom Tesfaghergish for his special support in epi-info Version 7 software installation and continuous support until we finish our thesis Mr. Nhom Kiros for his priceless effort on reviewing our thesis.

At last but not least we would like thank all the community of HAC for their support during data collection and the participants, who were willing to take part in the study.

\section{References}

${ }^{1}$ WHO Annual malaria global report 2015

$2 \mathrm{MoH}$ Eritrea Department of Public Health Division of Communicable Diseases Control

National Malaria Control Program: Malaria indicator and prevalence survey July-November (2012)"

3 WellCome trust "Early Diagnosis and treatment of malaria", http:/malaria.wellcome.ac.uk/docWTD023887.html)

4 (World Health Organization "Global Malaria progrmme Roll Back malaria partenership" from http:/www.who.int/mediacenter/factssheets/fs094/en/index.html), April 2010).

5 Omolade O. Okwa and Adejoke C. Ibidapo: The Malaria situation, perception of cause and treatment in a Nigerian University. Journal of Medicine and Medical Sciences Vol. 1(6) pp. 213-222 July 2010

6 Deborah Sumari, Angel Dillip, Vitalis Ndume, Joseph P. Mugasa, Paul S. Gwakisa1: Knowledge, attitudes and practices on malaria in relation to its transmission among primary school children in Bagamoyo district, Tanzania. Sumari et al. MWJ 2016, 7:2 
7 Mushtaq Ahmed, Rafaqat BOTA, Muhammad Salah Jamali, Adnan Aziz, Tayyaba Ilyas Dow Medical College; Civil hospital Karachi, Dow Medical College, Pakistan:MALARIA AND CONGO FEVER: AWARENESS AMONG UNIVERSITY STUDENTS Volume 2, Issue 1, 2013)

8 Daniel Kinyua M'Mauta (B. ED., SCI.),School of Public Health of Kenyatta University Assessment of Knowledge: Attitude and use of insecticide-treated nets among students in boarding secondary schools in Igembe district, Kenya April, 2014

i. World malaria report 2015.

ii. Layne SP. "Principles of Infectious Disease Epidemiology /" (PDF). EPI 220. UCLA Department of Epidemiology. Retrieved 2007-06-15.

\section{Figures}

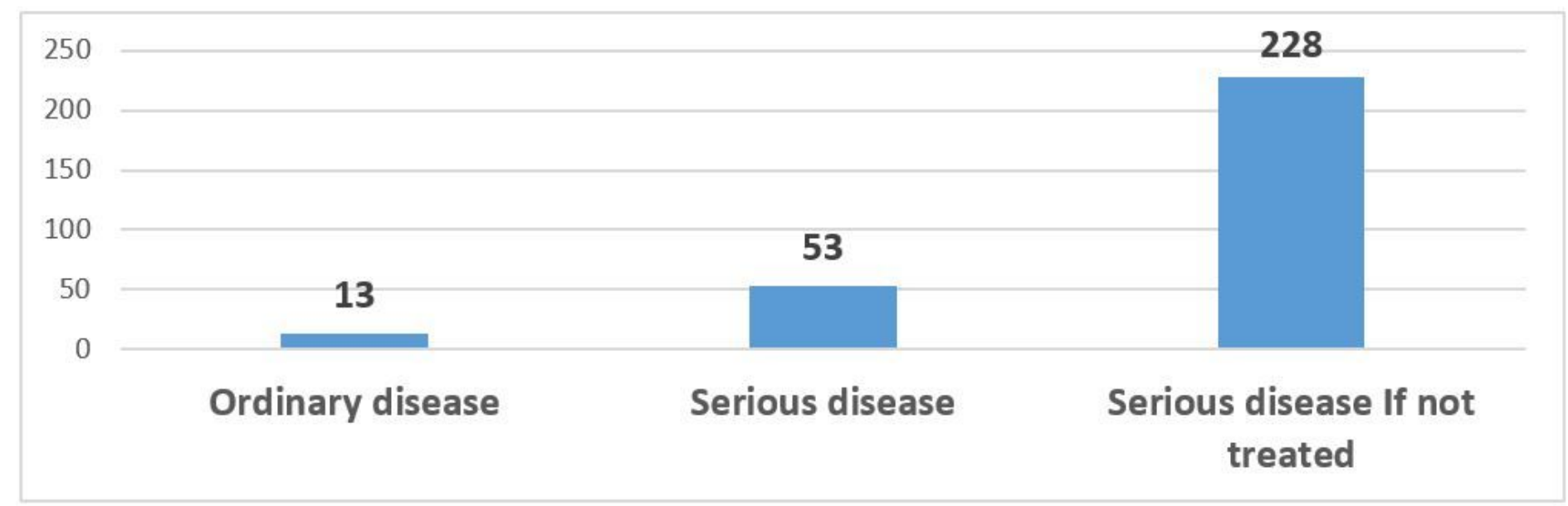

\section{Figure 1}

frequency of the respondent's opinion to the seriousness of malaria. 


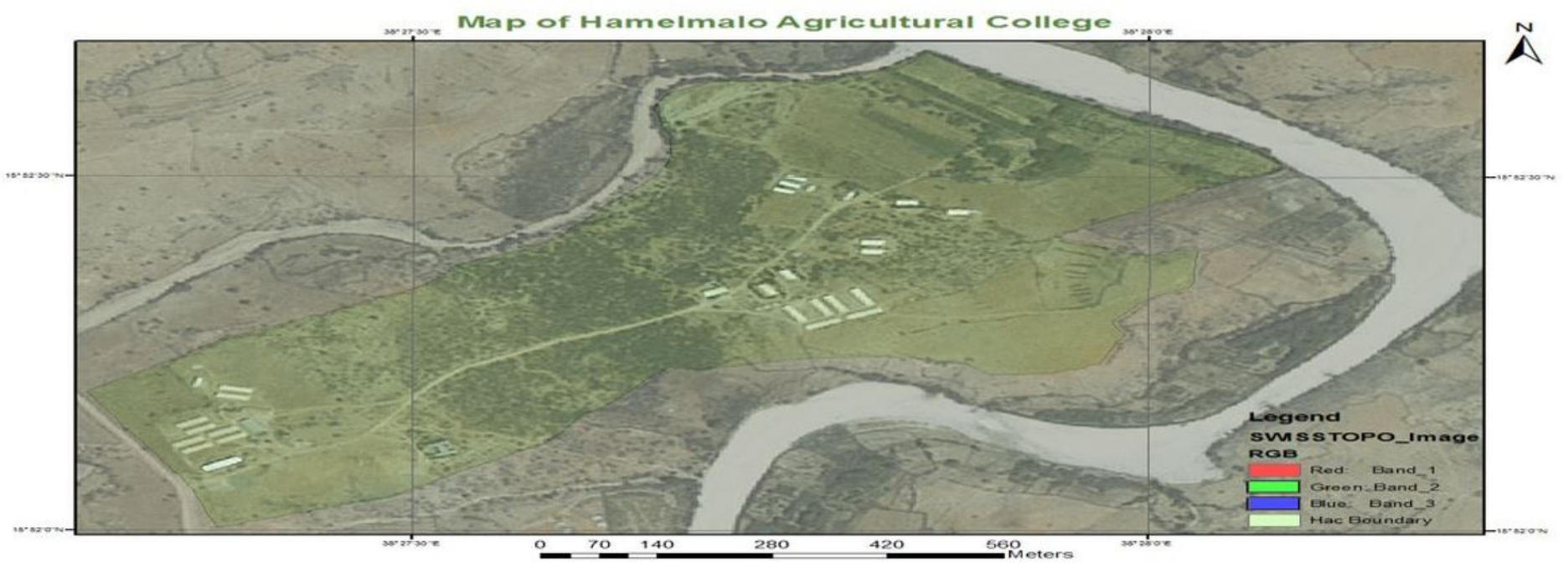

\section{Figure 2}

Map of hamelmalo Agriculture College Note: The designations employed and the presentation of the material on this map do not imply the expression of any opinion whatsoever on the part of Research Square concerning the legal status of any country, territory, city or area or of its authorities, or concerning the delimitation of its frontiers or boundaries. This map has been provided by the authors. 